\title{
Sialic Acid Glycoproteins Inhibit In Vitro and In Vivo Replication of Rotaviruses
}

\author{
Robert H. Yolken, Rodney Willoughby, Siok-Bi Wee, Robin Miskuff, and Steven Vonderfecht \\ Departments of Pediatrics and Pathology and Division of Comparative Medicine, The Johns Hopkins School \\ of Medicine, Baltimore, Maryland 21205
}

\begin{abstract}
We investigated the interactions of rotaviruses with glycoproteins and cells that support rotaviral replication. We found that a wide range of naturally occurring glycoproteins, including ovalbumins and ovomucoids from chicken and turkey eggs, and mucin derived from bovine submaxillary glands, inhibit the replication of rotaviruses in MA-104 cells. Our studies further indicated that the glycoproteins bind directly to rotaviruses and that virusglycoprotein binding is dependent largely upon interactions with sialic acid oligosaccharides. We found that accessible sialic acid oligosaccharides are required for efficient rotavirus infection of MA-104 cells, thus demonstrating that sialic acid oligosaccharides play an important role in the interactions of rotaviruses with both glycoproteins and cells that support rotaviral replication. Bovine submaxillary mucin and chicken ovoinhibitor can also prevent the shedding of rotavirus antigen and the development of rotavirus gastroenteritis in a mouse model of rotavirus infection. Our findings document that a range of glycoproteins inhibit the in vivo and in vitro replication of rotaviruses and suggest that the alteration in the quantity or chemical composition of intestinal glycoproteins is a potential means for the modulation of enteric infections.
\end{abstract}

\section{Introduction}

Rotaviruses are RNA viruses of the family Reoviradae, which have been identified as major etiological agents of symptomatic gastroenteritis in humans and animals (1-4). While rotaviruses are known to replicate in a number of tissue culture cell lines and in the intestinal epithelial cells of a wide range of animal species (5-7), little is known about the nature of the interactions of rotaviruses with cells that support rotaviral replication. Recently, a number of sialic acid-containing glycoproteins have been identified that modulate the interactions of pathogenic RNA viruses, such as myxoviruses, paramyxoviruses, picornaviruses and reoviruses, with epithelial cells (8-13). Because sialic acid-containing glycoproteins are major constituents of the human gastrointestinal tract and also are present in a number of human food products (14-17), such glycoproteins may be important determinants of host susceptibility to enteric infections. We thus investigated the role of sialic acid oligosaccharides on

This work was presented in part at the annual meeting of the Society for Pediatric Research, Washington, D.C., 5 May 1986.

Address reprint requests to Dr. Robert H. Yolken, Department of Pediatrics, Division of Infectious Diseases, CMSC 1102, Johns Hopkins Hospital, 600 N. Wolfe St., Baltimore, MD 21205.

Received for publication 2 June 1986.

J. Clin. Invest.

(C) The American Society for Clinical Investigation, Inc.

0021-9738/87/01/0148/07 \$1.00

Volume 79, January 1987, 148-154 the interactions of viruses and cells and on the ability of rotaviruses to cause gastrointestinal infections in experimental animals.

\section{Methods}

\section{Reagents}

Viruses. The SA-11 strain of rotavirus (antigenically related to human serotype 3) was originally obtained from Dr. H. Malherbe of Salt Lake City, UT and propagated in MA-104 cells using previously described methods (18). The WA (human serotype 1) and NCDV (bovine, serotype 6) strains of rotavirus were obtained from Dr. Richard Wyatt, National Institutes of Health, Bethesda, MD. The VA-70 (human, serotype 4) strain of rotavirus was obtained from Dr. G. Gerna, Milan, Italy. These viruses were propagated in MA-104 cell monolayers using standard cultivation methods, and the viral titers were determined by plaque enumeration (19). Cell lysates from uninfected MA-104 cells were prepared as described by Krah and Crowell (20). The EDIM strain of murine rotavirus was originally obtained from Dr. Michael Collins, Microbiological Associates, Rockville, MD. Murine rotavirus for animal inoculation was prepared from intestines collected from EDIM virus-infected suckling mice and was purified on $\mathrm{CsCl}$ gradients following previously described procedures (21). The infectivity of the purified virus preparation was determined by orally inoculating litters of 5-7-d-old mice with serial 10-fold dilutions of the viral stock. $3 \mathrm{~d}$ after inoculation, the mice were evaluated for diarrhea by examining the distal colon for the presence of liquid intestinal contents. The $100 \%$ infectious dose was defined as the highest dilutions of virus that produced diarrhea in all of the inoculated animals. In these studies, all mice inoculated with EDIM virus received a single $100 \%$ infectious dose.

Reagents. The following glycoprotein compounds were obtained from Sigma Chemical Company, St. Louis, MO: bovine submaxillary mucin, bovine serum albumin (BSA), chicken ovoinhibitor (type IV-O), chicken ovalbumin, turkey ovalbumin, turkey ovoinhibitor (type II-T), and fetuin. A dried egg white food preparation (spray dried angel-type egg whites) was obtained from Sonstegad Foods, Inc., Howard Lake, MN. These compounds were all found to be free of immunoglobulins as determined by enzyme immunoassay analyses (22). The mucins and ovalbumins were found to be free of protease inhibitory activity as determined by the method of Tidwell et al. (23). BSA, neuraminidase (from $C$. perfringens), beta-galactosidase (from $E$. coli), porcine trypsin, $N$-acetylneuramin-lactose, sodium borohydride, $N$-acetyl neuraminic acid, monosaccharides and lectins from Limulus polyphemus and other sources were also purchased from Sigma Chemical Co. Sheep erythrocytes were provided by Dr. Jerry Winklestein, Department of Pediatrics, Johns Hopkins Medical School, Baltimore, MD. Murine monoclonal antibody to the VP7 glycoprotein of the SA-11 strain of rotavirus was kindly provided by Dr. Harry Greenberg, Stanford University School of Medicine, Palo Alto, CA (24).

Animals. Pregnant CD-1 mice were purchased from a commercial supplier (Charles River Breeding Laboratories, Inc., Wilmington, MA). Housed in individual cages in positive pressure ventilation isolators, the mice were given food and water ad lib. The females were allowed to give birth naturally. Each pregnant animal was bled at the time of arrival in order to assure that none had rotavirus antibodies. Additionally, at the beginning of each experiment, blood and intestinal contents were collected from two animals in each litter to further verify that test animals were free of serum rotavirus antibody and intestinal rotavirus antigen. After 
preinoculation samples were collected, the suckling mice from all litters were pooled and then randomly divided equally among the dams. Suckling mice remained with the dams throughout the experiments.

Assay systems. The ability of the glycoproteins, erythrocytes, or lectins to inhibit rotavirus replication was measured by viral plaque neutralization analyses. Those were modified from assays that were originally developed for the measurement of antirotavirus-neutralizing antibodies (25). Briefly, MA-104 cells were grown to confluence on 6- or 12-well tissue culture microplates (Nunc A. S., Kamstrup, OK) in the presence of modified Eagle's minimum essential medium (EMEM) ${ }^{1}$ and $10 \%$ fetal bovine serum at $37^{\circ} \mathrm{C}$ in a $\mathrm{CO}_{2}$ environment. The cells were washed with serum-free media before use. Aliquots of glycoprotein or erythrocytes were diluted in EMEM with $0.5-1 \mu \mathrm{g} / \mathrm{ml}$ porcine trypsin, mixed with $\sim 100$ plaque forming units of virus, and absorbed onto the cells. After incubation at $37^{\circ} \mathrm{C}$ for $1 \mathrm{~h}$ the inoculum was decanted, the wells were washed with EMEM, and the cells were overlaid with an agarose mixture composed of $2 \times$ EMEM containing $2 \mu \mathrm{g} / \mathrm{ml}$ trypsin and $100 \mu \mathrm{g} / \mathrm{ml}$ DEAE-dextran mixed with an equal volume of $1.4 \%$ agarose type 1 (Sigma Chemical Co). After $48 \mathrm{~h}$ another agarose overlay, containing the above material plus neutral red solution at a concentration of 0.1 $\mathrm{mg} / \mathrm{ml}$ (Gibco, Grand Island, NY), was added to the cells. Plaques, as manifested by areas in which virus-infected cells were not stained with neutral red, were counted by visual inspection. For each concentration of glycoprotein or erythrocytes, a percentage inhibition was calculated by comparing the number of plaques formed in the presence of the glycoprotein with the number of plaques generated in control wells, incubated under similar conditions with virus but without glycoprotein.

In certain cases, the oligosaccharides of the glycoproteins were chemically reduced before testing by reaction with sodium borohydride with a method modified from that of Gentsch and Pacitti (12). For these reactions, a $10-\mathrm{mg}$ aliquot of the glycoprotein was suspended in $1 \mathrm{ml}$ of $0.1 \mathrm{M} \mathrm{NaOH}-0.8 \mathrm{M} \mathrm{NaBH}_{4}$ and incubated for $14 \mathrm{~h}$ at $37^{\circ} \mathrm{C}$ with constant magnetic stirring. At the end of the incubation, an additional $0.5-\mathrm{ml}$ aliquot of $\mathrm{NaOH}-\mathrm{NaBH}_{4}$ was added and the sample was incubated for an additional $4 \mathrm{~h}$ at $37^{\circ} \mathrm{C}$. The sample was then immediately cooled to $4^{\circ} \mathrm{C}$, and the concentration of $\mathrm{NaBH}_{4}$ was reduced to $0.2 \mathrm{M}$ by the addition of cold $\mathrm{H}_{2} \mathrm{O}$. The mixture was then adjusted to $\mathrm{pH} 5$ by adding glacial acetic acid. The sample was then dialyzed extensively against 0.01 $M$ phosphate-buffered saline (PBS) and tested as described above. Mock reactions in which PBS was substituted for the $\mathrm{NaOH}-\mathrm{NaBH}_{4}$ were performed to control for nonspecific degradation of the glycoprotein and loss during dialysis.

The effect of neuraminidase on the ability of sheep erythrocytes to inhibit replication of rotavirus in vitro was determined by incubating washed erythrocytes at concentrations of $0.1-10 \%$ with $5 \times 10^{-3} \mathrm{U}$ of neuraminidase from $C$. perfringens. After incubation for $2 \mathrm{~h}$ at $37^{\circ} \mathrm{C}$, the enzyme was removed from the erythrocytes by centrifugation and the cells were washed in EMEM. The enzyme-treated erythrocytes were then added to the MA-104 cells, which were then infected with virus for $1 \mathrm{~h}$ at $37^{\circ} \mathrm{C}$. The virus-erythrocyte mixture was decanted, agarose overlay was added, and the cells were processed as described above. Untreated erythrocytes and erythrocytes treated with equivalent concentrations of beta-galactosidase were evaluated in a similar manner to serve as controls.

The effect of enzymes on the ability of MA-104 cells to support viral replication was determined by reacting the cells with varying concentrations of neuraminidase from $C$. perfringens or beta-galactosidase from $E$. coli for $4 \mathrm{~h}$ at $37^{\circ} \mathrm{C}$. After this incubation, the enzyme was removed by washing and replaced with EMEM. Virus was then added at measured time intervals following enzymatic treatment, and the cells were monitored for viral replication as described above.

The interaction of bovine submaxillary mucin with rotavirus was investigated by measuring the binding of radiolabeled virus with immobilized mucin. For these experiments, the SA-11 strain of rotavirus was isolated from infected MA-104 cells by Freon extraction and purified

1. Abbreviations used in this paper: EMEM, Eagle's minimum essential medium; OD, optical density; PBST, phosphate-buffered solution containing $0.5 \%$ Tween-20. by sedimentation in a $40-60 \%$ metrizamide gradient at $120,000 \mathrm{~g}$ for 48 $h$. Visible bands containing virus as determined by enzyme immunoassay (18) were pooled and labeled with ${ }^{125}$ I by reaction with immobilized oxidant (Iodobeads; Pierce Chemical Co., Rockford, IL) by the method of Markwell (26). The labeled virus was separated from unincorporated ${ }^{125}$ I by filtration through Sephadex G-25 in a 6-cm disposable column (Pharmacia Inc., Piscataway, NJ). This method of labeling generally resulted in a specific activity of $\sim 10^{6} \mathrm{cpm} / \mu \mathrm{g}$ of viral protein.

Microtiter well strips (Immulon II; Dynatech Laboratories, Inc., Alexandria, VA) were coated with bovine submaxillary mucin diluted to $10 \mu \mathrm{g} / \mathrm{ml}$ in $0.01 \mathrm{M}$ carbonate buffer (pH 9.0). After an overnight incubation at $4^{\circ} \mathrm{C}$, the strips were washed five times with PBS containing $0.5 \%$ Tween-20 (PBST), and ${ }^{125} \mathrm{I}$-labeled virus was added to the well. Following an incubation for $2 \mathrm{~h}$ at $37^{\circ} \mathrm{C}$, the wells were washed five times with PBST, and the amount of ${ }^{125} \mathrm{I}$ binding to the wells was measured by means of standard gamma counting instrumentation (G. D. Searle and Co., Skokie, IL). The binding of virus to the solid phase was documented by eluting the material from the solid phase by reaction with Laemmli buffer (27). The eluted material was separated by electrophoresis through a $10 \%$ polyacrylamide gel for $17 \mathrm{~h}$ at $70 \mathrm{~V}$, and the labeled components were identified by autoradiography for $\sim 2 \mathrm{~d}$ at $-70^{\circ} \mathrm{C}$ with a Quanta III intensifying screen (Dupont Inc., Wilmington, DE).

The ability of oligosaccharides, glycoproteins, and other macromolecules to inhibit the binding of radiolabeled rotavirus to mucin immobilized onto the solid phase was determined by the following method. The potential inhibitor was diluted in PBS, mixed with $\sim 100,000 \mathrm{cpm}$ of rotavirus labeled with ${ }^{125} \mathrm{I}$ as described above. The virus-inhibitor mixture was added to microtiter wells coated with mucin as described above. After incubation for $90 \mathrm{~min}$ at $37^{\circ} \mathrm{C}$, the wells were washed with PBST, and the amount of ${ }^{125} \mathrm{I}$ binding to the wells was counted as described above. For each compound a percentage inhibition was calculated by determining the counts bound to the solid phase mucin in the presence of the added inhibitor, as compared with the binding of equal amounts of virus incubated in PBS under similar reaction conditions.

The ability of the glycoproteins to inhibit the intestinal replication of rotaviruses was evaluated in a murine model of rotavirus infection by the following method. One part of a suspension of EDIM virus containing $10100 \%$-infectious doses $/ 0.1 \mathrm{ml}$, prepared as described above, was added to nine parts of the test compound at a concentration of 10 $\mathrm{mg} / \mathrm{ml}$ and incubated at $37^{\circ} \mathrm{C}$ for $30 \mathrm{~min}$. The stock EDIM virus solution was diluted in PBS containing $0.01 \mathrm{M} \mathrm{CaCl}_{2}$ and $0.01 \mathrm{M} \mathrm{MgCl}_{2}$. Test compounds were dissolved in sterile, deionized water. 6- to 8-d-old suckling mice were given $0.1 \mathrm{ml}$ of the virus-compound mixture intragastrically via a 24-gauge gastric gavage needle. 2 or $4 \mathrm{~d}$ later the intestinal tract was examined for diarrhea and then individually collected and frozen at $-70^{\circ} \mathrm{C}$ until assayed for rotavirus antigen with a solid phase enzyme immunoassay utilizing immune reagents directed at EDIM antigen (22). Wells of polystyrene microtiter plates (Immulon II; Dynatech Laboratories, Inc.) were coated overnight at $4^{\circ} \mathrm{C}$ with either nonimmune chicken serum or chicken anti-EDIM virus serum diluted in carbonate buffer (pH 9.2). The wells were washed with PBS-0.05\% Tween 20, covered with test intestinal homogenates, and incubated overnight at $4^{\circ} \mathrm{C}$. The amount of intestinal rotavirus antigen that bound to the antibody on the solid phase was quantitated by the addition of guinea pig anti-EDIM virus serum followed by peroxidase-labeled, affinity-purified, goat antibody to guinea pig IgG (heavy and light chains) (Kirkegaard and Perry Laboratories, Inc., Gaithersburg, MD) and substrate consisting of 0.4 mg $\alpha$-phenylene-diamine and $0.4 \mu \mathrm{l}$ of $30 \% \mathrm{H}_{2} \mathrm{O}_{2} / \mathrm{ml}$ of $0.01 \mathrm{M}$ citrate buffer (pH 5). Enzymatic activity was quantitated in a spectrophotometer (Bio-Tek Instruments, Inc., Burlington, VT) at a wave length of $450 \mathrm{~nm}$. The net optical density (OD) of a specific test sample was determined by subtracting the OD values obtained from wells coated with the nonimmune chicken serum from the OD readings in wells coated with the chicken anti-EDIM virus serum. Intestinal homogenates obtained from EDIM-virus-free or EDIM-virus-infected suckling mice served as the negative and positive controls, respectively. Plate-to-plate variation in OD readings was controlled by expressing individual test samples as a 
percentage of the positive control samples on that particular plate. Values obtained for the test compound-treated and control-treated animals were compared by Wilcoxon Rank Sum analysis to determine statistical significance.

\section{Results}

Effect of glycoproteins on rotavirus replication. Initial experiments were directed at determining the effect of a number of naturally occurring glycoproteins on the in vitro replication of rotaviruses as evidenced by the ability of the compounds to inhibit the generation of plaques after the infection of MA-104 cells with the SA-11 strain of rotavirus. As depicted in Fig. 1, incubation of virus with ovomucoid and ovalbumin glycoproteins from turkeys and chickens resulted in $50 \%$ inhibition of rotavirus replication at concentrations of $<10 \mu \mathrm{g} / \mathrm{ml}$. Similarly, a crude preparation of powdered egg white used as a food supplement was also capable of inhibiting $50 \%$ of the rotavirus replication at a concentration of $<10 \mu \mathrm{g} / \mathrm{ml}$. Incubation of virus with bovine fetuin resulted in a $50 \%$ decrease in viral replication at a concentration of $<100 \mu \mathrm{g} / \mathrm{ml}$ and incubation with bovine submaxillary mucin resulted in $50 \%$ inhibition at a concentration between 100 and $1,000 \mu \mathrm{g} / \mathrm{ml}$. The inhibitory effect of the glycoproteins was totally eliminated by reduction with $0.8 \mathrm{M}$ sodium borohydride (Fig. 1) but not by treatment of the glycoproteins with $0.1 \mathrm{M} \mathrm{NaOH}$, extensive dialysis, or heating at $70^{\circ} \mathrm{C}$ for $30 \mathrm{~min}$. The glycoprotein compounds were also found to inhibit in vitro replication of other strains of rotavirus, including WA (human, serotype 1), and VA-70 (human, serotype 4), strains of virus at concentrations similar to those that inhibited replication of the SA-11 strain of rotavirus (data not depicted).

We also investigated the ability of low molecular weight oligosaccharides and other compounds to inhibit replication of SA-11. A small amount of inhibition was also noted after incubation of virus with $\mathrm{N}$-acetyl neuraminic acid monosaccharide (sialic acid) at a concentration of $1 \mathrm{mg} / \mathrm{ml}$. Inhibition was not observed with $N$-acetyleneuramin-lactose, $N$-acetylglucosamine, $\mathrm{N}$-acetylgalactosamine, glucose, fructose, galactose, or mannose. No inhibition was noted following the incubation of virus with BSA or dextran sulfate.

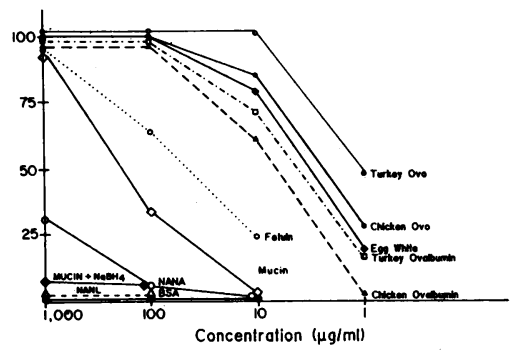

Figure 1. Inhibition of rotavirus replication by glycoproteins. Glycoproteins and oligosaccharides at the indicated concentrations were incubated with $10^{3}$ plaque forming units of the SA11 strain of rotavirus and added to MÁ-104

cells. After addition of an agarose overlay and incubation for $3 \mathrm{~d}$, the number of plaques resulting from the infection of the cells was enumerated as described in the text. For each concentration of glycoprotein the percentage inhibition of rotavirus infection was calculated by comparing the number of plaques generated after incubation of virus with the inhibitor with the number of plaques generated by virus alone. The glycoproteins, oligosaccharides, and egg white preparation were obtained and prepared as described in the text. BSA, bovine serum albumin; NANA, $\mathrm{N}$-acetyl neuraminlactose; $M$ ucin $+\mathrm{NaBH}_{4}$, bovine submaxillary mucin reduced by reaction with sodium borohydride as described in the text. Reaction of the virus with other sugars such as glucose, fructose, galactose, mannose, $N$-acetyl glucosamine, and $\mathrm{N}$-acetyl galactosamine did not result in any measurable inhibition of rotavirus replication at concentrations up to $1,000 \mu \mathrm{g} / \mathrm{ml}$.

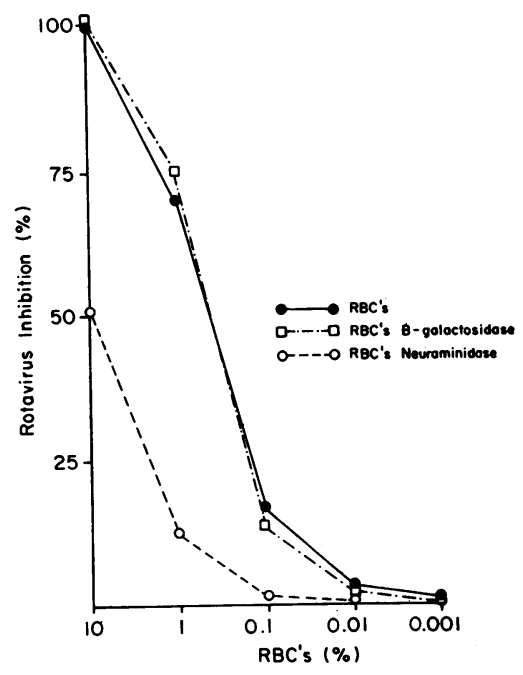

Figure 2. Effect of erythrocytes on rotavirus replication. Sheep erythrocytes were diluted in minimum essential medium to the indicated percentage and incubated on MA-104 cells with 100 plaque forming units of the SA-11 strain of rotavirus for $2 \mathrm{~h}$ at $37^{\circ} \mathrm{C}$. Cells were also incubated with virus and erythrocytes that had been modified by reaction with $0.1 \mathrm{U}$ of neuraminidase or beta-galactosidase as described in the text. After removal of the erythrocytes and virus, an agarose overlay was added and the growth of rotavirus was measured by plaque generation as described in the text. For each concentration of erythrocytes, a percentage inhibition was calculated by comparing the number of plaques generated after incubation of virus with the erythrocytes compared with the number of plaques generated by virus alone.

The oligosaccharide linkages involved in inhibition of rotavirus growth were further examined by investigating the effect of sheep erythrocytes on rotavirus growth. As depicted in Fig. 2 , sheep erythrocytes were capable of inhibition of rotavirus replication at concentrations as low as $0.1 \%$ (vol/vol). The inhibitory effect of the erythrocytes was markedly reduced by their pretreatment with $0.1 \mathrm{U}$ of neuraminidase for $4 \mathrm{~h}$ at $37^{\circ} \mathrm{C}$. Treatment of the erythrocytes with beta-galactosidase or other glucosidases did not result in a substantial decrease in inhibitory activity. Human type $A, B, A B$, and $O$ erythrocytes could also inhibit rotavirus growth at equivalent concentrations (data not shown).

Enzymatic analysis was also undertaken to examine the glycoprotein components of the surface of MA-104 cells involved in rotavirus interactions. As depicted in Fig. 3, the treatment of cells with as little as $10^{-3} \mathrm{U}$ of neuraminidase for $2 \mathrm{~h}$ at $37^{\circ} \mathrm{C}$ resulted in a marked decrease in the ability of the cells to support rotavirus replication. This inhibitory effect was demonstrable for up to $28 \mathrm{~h}$ after the enzymatic treatment of the cells. Treatment of the cells with beta-galactosidase or other glucosidases did not result in an alteration of rotavirus replication.

The role of specific oligosaccharides in cell-virus interactions was further examined by investigating the ability of lectins with defined oligosaccharide-binding specificity to inhibit rotavirus replication. We found that lectin derived from Limulus polyphemus, which displays specific interactions with sialic acid oligosaccharides $(28,29)$, could inhibit replication of SA-11 in MA104 cells at concentrations as low as $10 \mu \mathrm{g} / \mathrm{ml}$. Significant levels of inhibition were not found following incubation with lectins purified from Pisum sativum, Glycine max, Triticum vulgaris, Lens culinaris or Ptilota plumosa at concentrations as high as $100 \mu \mathrm{g} / \mathrm{ml}$. These lectins display binding primarily to glucose, galactosamine, glucosamine, mannose, and galactose oligosaccharides, respectively.

Mechanism of glycoprotein interactions. We performed additional investigations to elucidate the mechanism of the inhib- 


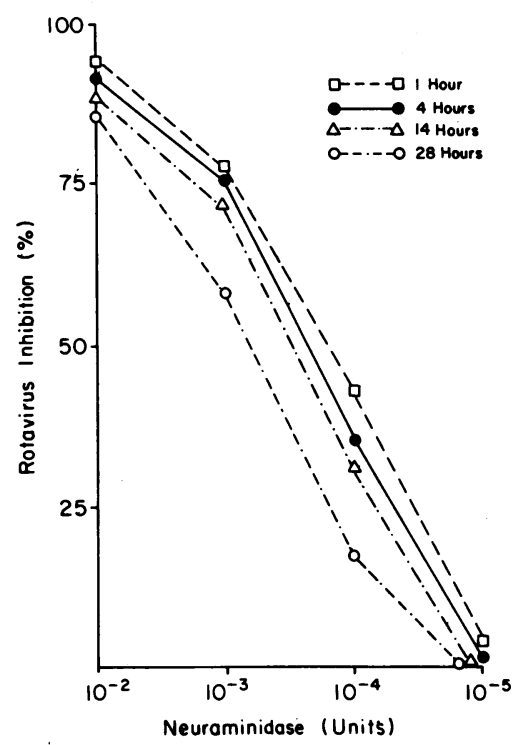

generation as described in the text. For each reacti hibition was calculated by comparison with mock-treated cells processed in a similar manner but without reaction with neuraminidase.

itory effect of the glycoproteins on the in vitro replication of rotavirus. We thus pretreated MA-104 cells with bovine submaxillary mucin at concentrations of $10 \mathrm{mg} / \mathrm{ml}$ for $2 \mathrm{~h}$ at $37^{\circ} \mathrm{C}$ but removed the glycoprotein by washing the cells with EMEM before cellular infection. As depicted in Fig. 4, the removal of the glycoprotein resulted in the elimination of its inhibitory effect on subsequent rotavirus replication. On the other hand, the incubation of virus with submaxillary mucin at a concentration of $10 \mathrm{mg} / \mathrm{ml}$ led to inhibition of viral growth even when the mucin was diluted to a final concentration of as little as $1 \mu \mathrm{g} /$ $\mathrm{ml}$ immediately before addition to the cells. At this concentration mucin did not inhibit rotaviral replication when added to the

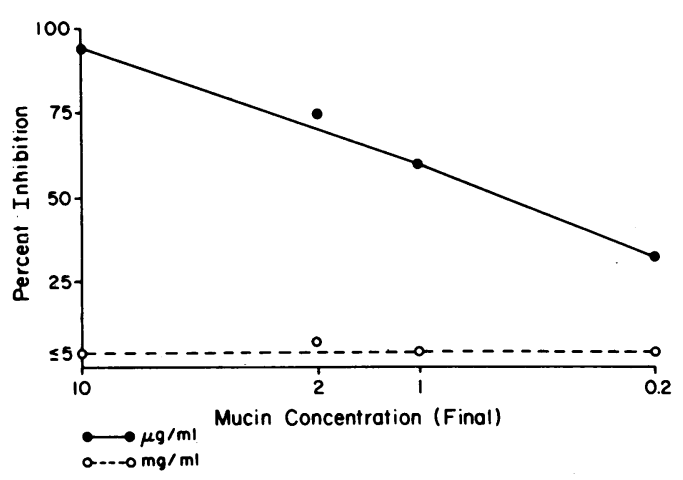

Figure 4. Inhibition of rotavirus replication by mucin incubated with cells or virus. (Open circles) Bovine submaxillary mucin was incubated for $2 \mathrm{~h}$ at $37^{\circ} \mathrm{C}$ on MA-104 cell monolayers at the indicated concentrations. After removal of the mucin by washing with EMEM, the SA11 strain of rotavirus was added to the cells at a concentration of $10^{3}$ plaque forming units/ml and viral growth was monitored by counting viral plaques. (Solid circles) SA-11 at varying concentrations was incubated with mucin at a concentration of $10 \mathrm{mg} / \mathrm{ml}$ for $2 \mathrm{~h}$ at $37^{\circ} \mathrm{C}$.

The virus-mucin mixture was diluted to the indicated concentration of mucin. The mixture was then added to the cells and processed for plaque enumeration as described in the text. cells with virus (Fig. 1). Similar results were found with the ovalbumin and ovomucoid inhibitors of rotavirus replication.

Interactions with radiolabeled virus. We also investigated the interaction of virus with glycoprotein by measuring the binding of radiolabeled virus to mucin that had been immobilized onto the wells of polystyrene microtiter plates. As depicted in Fig. 5, bovine submaxillary mucin immobilized onto the solid phase was capable of interacting with rotavirus, as evidenced by the binding of radiolabeled bands that migrated at molecular weight compatible with VP3 and VP7, the major outer capsid proteins of rotaviruses $(30,31)$. In addition, radiolabeled virus bound to chicken yolk immunoglobulins containing antirotavirus antibodies and monoclonal antibodies to VP7, as well as sheep erythrocytes and purified preparations of cellular membranies derived from MA-104 cells. On the other hand, radiolabeled virus did not bind to uncoated wells or to wells coated with control yolk immunoglobulins obtained from unimmunized chickens.

We also used this solid phase binding system to investigate the sugar specificity of the binding of virus to mucin. As depicted in Fig. 6, the binding of virus to solid-phase mucin was inhibited by $N$-acetyl neuraminic acid (sialic acid) at concentrations as

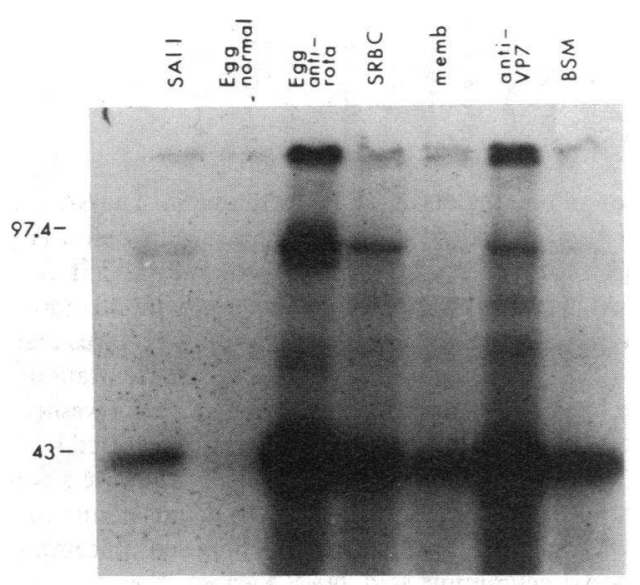

Figure 5. Polyacrylamide gel electrophoresis of radiolabeled virus binding to solid-phase mucin. The SA-11 strain of rotavirus was purified by ultracentrifugation in a $40-60 \%$ metrizamide gradient and labeled with ${ }^{125} \mathrm{I}$ by reaction with immobilized oxidant as described in the text. The virus was reacted to polystyrene microtiter wells coated with mucin, antibody, erythrocytes, or purified membrane preparations. After incubation for $2 \mathrm{~h}$ at $37^{\circ} \mathrm{C}$, the wells were washed and the bound virus was eluted with SDS buffer and resolved by polyacrylamide gel electrophoresis and autoradiography. The preparations added to the lanes are as follows: SA-11, radiolabeled, purified SA-11 run through the gel without prior binding to the solid phase; egg normal, virus eluted from the solid phase coated with immunoglobulins isolated from chicken eggs without antibody to rotavirus; egg antirota, virus eluted from the solid phase coated with immunoglobulins isolated from chicken eggs immunized with SA-11; SRBC, virus eluted from the solid phase coated with sheep erythrocytes at a concentration of $0.1 \%$ (vol/vol); memb, virus eluted from the solid phase coated with membranes purified from MA-104 cells; anti-VP7, virus eluted from the solid phase coated with monoclonal antibody to the viral protein VP7; BSM, virus eluted from the solid phase coated with bovine submaxillary mucin at a concentration of $10 \mu \mathrm{g} / \mathrm{ml}$. The indicated molecular weights are the calculated positions of the major rotavirus outer membrane glycoproteins VP3 and VP7. Photograph represents an $\sim 25 \%$ reduction from the original. 


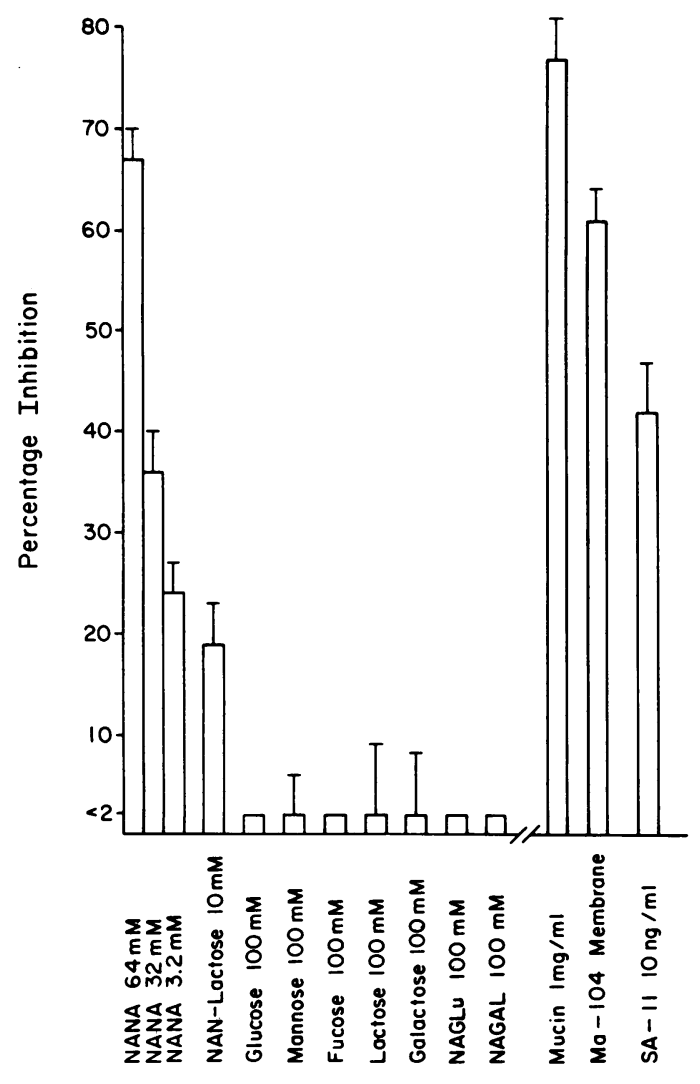

Figure 6. Inhibition of binding of ${ }^{125}$ I rotavirus to mucin. The SA-11 strain of rotavirus was cultured in MA-104 cells, purified by ultracentrifugation through a metrizamide gradient, and labeled with ${ }^{125} \mathrm{I}$ as described in the text. The labeled virus was incubated with the indicated compounds and added to polystyrene microtiter well strips that had been coated with bovine submaxillary mucin at a concentration of $10 \mu \mathrm{g} / \mathrm{ml}$. After incubation for $2 \mathrm{~h}$ at $37^{\circ} \mathrm{C}$, the strips were washed and the amount of ${ }^{125} \mathrm{I}$ virus binding to the mucin was measured by means of gamma counting instrumentation. For each substance a percentage inhibition was calculated by comparing the counts bound in the presence and absence of the substance at the indicated concentrations. NANA, $N$-acetyl neuraminic acid, NAN-Lactose, $N$-acetyl neuraminlactose; NAGLU, $N$-acetyl glucosamine; NAGAL, $N$-acetyl galacatosamine.

low as $3 \mathrm{mM}$ and by $\mathrm{N}$-acetyleneuramin lactose at a concentration of $10 \mathrm{mM}$. Binding was also inhibited by incubation of the ${ }^{125}$ I-labeled rotavirus with unlabeled rotavirus and by incubation with cell membrane preparations isolated from MA-104 cells. On the other hand, binding was not inhibited by glucose, fucose, mannose, galactose, $\mathrm{N}$-acetyl glucosamine, or other sugars at concentrations of $100 \mathrm{mM}$. Binding of virus was also significantly decreased by treatment of the solid-phase mucin with neuraminidase and by chemical reduction of the mucin with sodium borohydride.

Effect of glycoproteins on in vivo replication. We also evaluated the ability of the glycoprotein compounds to inhibit intestinal viral replication in a mouse model of rotavirus infection. As depicted in Fig. 7, bovine submaxillary mucin and chicken ovoinhibitor prevented symptomatic disease and significantly inhibited intestinal viral replication up to $4 \mathrm{~d}$ after infection. Chicken ovalbumin also resulted in a significant decrease in the amount of rotavirus replication measured $2 \mathrm{~d}$ after infection. Other glycoprotein compounds resulted in decreases in the rate of intestinal rotavirus replication, but the alteration in antigen levels did not reach statistical significance. The intestinal replication of rotavirus measured at $2 \mathbf{d}$ following infection was also inhibited by the feeding of sheep erythrocytes along with the rotavirus inoculum. However, the inhibitory activity of the erythrocytes was reduced by treatment of the erythrocytes with $1 \mathrm{U}$ of neuraminidase at $37^{\circ} \mathrm{C}$ for $1 \mathrm{~h}$ before viral incubation.

\section{Discussion}

Our studies document that a wide range of glycoprotein compounds are capable of inhibiting the in vitro replication of rotaviruses and preventing the development of rotavirus gastroenteritis in experimentally infected animals. Kinetic studies of the inhibition of rotavirus replication in tissue culture indicate that the glycoproteins exert their inhibitory effect by interacting directly with rotaviruses rather than with the cells that support viral replication. This concept is supported by our finding that radiolabeled virus bound efficiently to mucin that was immobilized onto a solid phase surface. While the mechanism of virusglycoprotein binding is not known with certainty, it is likely that the glycoproteins interact with the viruses by binding to one of the outer capsid proteins of rotavirus, such as VP7 or VP3 (30, 31). The molecular nature of the binding of virus to mucin should be the subject of additional investigations.

While the glycoproteins that we tested contain a number of different oligosaccharide side chains, the results of our studies indicate that sialic acid oligosaccharides play a major role in the interactions between rotaviruses and the glycoproteins with inhibitory activity. For example, while oligosaccharides containing $\mathrm{N}$-acetylneuraminic acid were found to inhibit the binding of radiolabeled rotavirus to solid phase mucin, other sugars, including the closely related amine sugars $N$-acetylglucosamine and $\mathrm{N}$-acetylgalactosamine, failed to inhibit this interaction. In addition, the ability of sheep erythrocytes to inhibit the in vitro and in vivo replication of rotaviruses was eliminated by the treatment of the erythrocytes with neuraminidase. The importance of sialic acid oligosaccharides in the interaction of virus with the glycoprotein inhibitors led us to investigate the role of sialic acid residues on the binding of rotavirus to cells that support viral replication. In fact, the treatment of MA-104 cells with neuraminidase resulted in a significant decrease in the ability of the cells to support viral replication. Similarly, viral replication was inhibited by incubation of the cells with sialic acid-binding lectin from Limulus polyphemus, whereas many other lectins failed to inhibit viral replication. Our findings that sialic acid oligosaccharide side chains are involved both in the binding of virus to glycoproteins and in the interaction of virus with MA104 cells suggest that rotaviruses interact with the glycoprotein inhibitors by mechanisms similar to those by which rotaviruses bind to cells that support viral replication. This possibility is supported by our finding that preparations of surface membranes purified from MA-104 cells are capable of inhibiting the binding of radiolabeled virus to solid-phase mucin (Fig. 5). Our findings are consistent with those of Bastardo and Holmes (32), who demonstrated that sialic acid oligosaccharides are the principal determinants of the interaction of rotavirus hemagglutinin with erythrocytes, as well as with the finding of Keljo and Smith (33) that the binding of radiolabeled rotaviruses to MA-104 cells is significantly reduced by the treatment of cells with neuraminidase. In addition, our findings are consistent with the important 


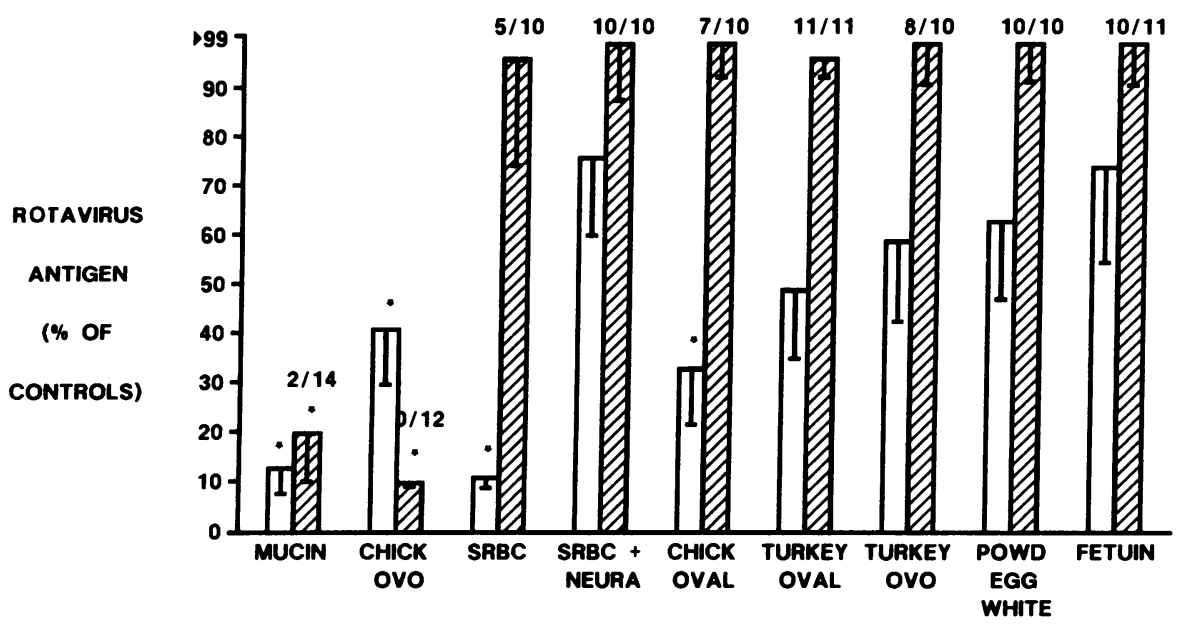

TEST COMPOUND
Figure 7. Effect of glycoproteins and erythrocytes on the in vivo replication of murine rotavirus. Glycoprotein compounds at a concentration of $10 \mathrm{mg} / \mathrm{ml}$ or erythrocytes at a concentration of $2 \%(\mathrm{vol} / \mathrm{vol})$ were mixed with the EDIM strain of murine rotavirus, incubated at $37^{\circ} \mathrm{C}$ for $30 \mathrm{~min}$, and administered intragastrically to 6-8-d-old rotavirus seronegative mice. The levels of rotavirus antigens were measured in the intestinal contents on day 2 and day 4 after infection by means of a solid-phase enzyme immunoassay, and the mice were observed for evidence of gastroenteritis on day 4 following infection as described in the text. The assay results are expressed as the percentage of ELISA activity as compared with control animals infected with an equal amount of virus in the absence of inhibitor as described in the text. Bars indicate the

mean levels of EDIM antigen and the standard errors of the means for each compound (open bars, day 2; hatched bars, day 4). The numbers indicate the number of animals with symptomatic gastroenteritis as evidenced by liquid intestinal contents/the number of animals examined on day 4 after infection. (*) $P<0.05$ compared with control group by Wilcoxon Rank Sum Test. MUCIN, bovine submaxillary mucin, CHICK OVO, ovoinhibitor from chicken eggs, SRBC, sheep red blood cells, SRBC + NEURA, sheep red blood cells treated with 1 U of neuraminidase for $1 \mathrm{~h}$ at $37^{\circ} \mathrm{C}$; CHICK OVAL, ovalbumin from chicken eggs; TURKEY OVAL, ovalbumin derived from turkey eggs; TURKEY OVO, ovoinhibitor derived from turkey eggs; POWD EGG WHITE, egg white food preparation.

role of sialic acid receptors in the cell-virus interactions of other RNA viruses, such as reoviruses, enteroviruses, influenza viruses, parainfluenza viruses, and respiratory syncytial viruses (8-13). The possible relationship between sialic acid-containing glycoproteins and cellular binding sites for rotaviruses should be investigated by more detailed analyses of the binding and uptake of rotaviruses by susceptible cells and by the purification and characterization of rotavirus cellular receptors.

In addition to preventing the in vitro replication of rotaviruses, bovine submaxillary mucin and chicken ovoinhibitor were capable of inhibiting the intestinal replication of rotaviruses and preventing the development of symptomatic rotavirus gastroenteritis in experimentally infected infant mice. Intestinal infection was also reduced by the feeding of sheep erythrocytes along with virus, whereas erythrocytes treated with neuraminidase were ineffective at reducing infection. These findings suggest that interactions involving sialic acid oligosaccharides are also important in rotavirus infections in vivo. It is of note that, while bovine submaxillary mucin was less effective than the other glycoproteins on a weight basis for the inhibition of rotavirus replication in tissue culture, it proved to be one of the most effective compounds for prevention of rotavirus gastroenteritis in the animal model system. The reasons for the differential efficacy of mucin in the animal model and in vitro systems is not known with certainty but may be related to the nature of rotavirus binding to intestinal cells or to differences in the intestinal metabolism of the glycoproteins. The interaction of mucins with rotaviruses and other pathogenic intestinal viruses is of interest because mucins are secreted by goblet cells located throughout the intestinal tract and mucin secretion can be altered by developmental changes, pathological gastrointestinal disease states, and changes in gastrointestinal microflora $(14-17,28,29)$. It is thus possible that variations in the quantity or character of mucinous glycoproteins might modulate the intestinal replication of enteric viruses and that differential levels or chemical forms of intestinal glycoproteins might be partially responsible for the well-described age and species determinants of susceptibility to enteric viral infections $(1,2,34)$. In addition, the fact that many food products contain mucinous and other sialic acid-containing glycoproteins $(35,36)$ suggests that dietary alterations might also have a modulating effect on rotavirus infections.

Our studies suggest that the inhibition of intestinal replication of rotavirus by means of glycoprotein interactions may be a potential strategy for the modulation of rotavirus infection in humans and animals. The ability to prevent intestinal infection by nonimmunological means might prove to be particularly important for prevention of disease in newborns, immunocompromised patients, and other individuals incapable of mounting an effective immune response to active immunization (37-39). In addition, the fact that mucins and other sialic acid-containing glycoproteins can also modulate the in vitro replication of reoviruses (12) and the intestinal binding of cholera toxin (40) suggests that glycoproteins might be used to inhibit the intestinal replication of a number of enteric pathogens. The pharmacokinetic parameters of the interaction of glycoproteins with enteric pathogens should be the subject of further investigations. Of particular note will be the dose, route of administration, and time course required for the effective prevention of symptomatic intestinal infection. The development of practical modalities for inhibiting the intestinal replication of a range of pathogenic intestinal viruses may represent a major advance in the prevention of intestinal viral infections in infants, young children, and other individuals at high risk for significant degrees of morbidity and mortality from infectious gastroenteritis.

\section{Acknowledgments}

This work was supported by grant R01 AM-33089-03 from the National Institutes of Health. Dr. Vonderfecht is a recipient of a Special Emphasis Research Career Award from the Division of Research Resources. Dr. Willoughby is a recipient of a Harriet Lane Home Research Fellowship. 


\section{References}

1. Cukor, G., and N. R. Blacklow. 1984. Human viral gastroenteritis. Microbiol. Rev. 48:157-179.

2. Kapikian, A. Z., and R. H. Yolken. 1985. Rotavirus. Principles and Practice of Infectious Diseases. 121:933-944.

3. Flores, J., O. Nakagomi, T. Nakagomi, R. Glass, M. Gorziglia, J. Askaa, Y. Hoskins, I. Perez-Schael, and A. Z. Kapikian. 1986. The role of rotaviruses in pediatric diarrhea. Ped. Inf. Dis. 5:S53-S62.

4. Estes, M. K., E. L. Palmer, and J. F. Obijesk. Rotaviruses: a review. Curr. Top. Microbiol. Immunol. 105:123-184.

5. Wyatt, R. G., C. A. Mebus, R. H. Yolken, A. R. Kalica, H. D. James, Jr., A. Z. Kapikian, and R. M. Chanock. 1979. Rotaviral immunity in gnotobiotic calves: heterologous resistance to human virus induced by bovine virus. Science (Wash. DC). 203:548-550.

6. Riepenhoff-Talty, M., P. Lee, P. J. Carmody, H. J. Barrett, and P. L. Ogra. 1982. Age-dependent rotavirus-enterocyte interactions. Proc. Soc. Exp. Biol. Med. 170:146-154.

7. Eydelloth, R. S., S. L. Vonderfecht, J. F. Sheridan, L. D. Enders, and R. H. Yolken. 1984. Kinetics of viral replication and local and systemic immune responses in experimental rotavirus infection. J. Virol. 50:947-950.

8. Suzuki, Y., M. Matsunaga, and M. Matsumoto. 1985. N-Acetylneuraminyllactosylceramide, $\mathrm{GM}_{3}-\mathrm{NeuAc}$, a new influenza A virus receptor which mediates the absorption-fusion process of viral infection. J. Biol. Chem. 260:1362-1365.

9. Suzuki, Y., T. Suzuki, and M. Matsumoto. 1983. Isolation and characterization of receptor sialoglycoprotein for haemagglutinating virus of Japan (Sendai virus) from bovine erythrocyte membrane. J. Biochem. 93:1621-1633.

10. Utagawa, E. T., K. Miyamura, A. Mukoyama, and R. Kono. 1982. Neuraminidase-sensitive erythrocyte receptor for enterovirus type 70. J. Gen. Virol. 63:141-148.

11. Armstrong, G. D., R. W. Paul, and P. W. K. Lee. 1984. Studies on reovirus receptors of $\mathrm{L}$ cells: virus binding characteristics and comparison with reovirus receptors of erythrocytes. Virology. 138:37-48.

12. Gentsch, J. R., and A. F. Pacitti. 1985. Effect of neuraminidase treatment of cells and effect of soluble glycoproteins on type 3 reovirus attachment to murine L cells. J. Virol. 56:356-364.

13. Co, M. S., G. N. Gaulton, B. N. Fields, and M. I. Greene. 1985. Isolation and biochemical characterization of the mammalian reovirus type 3 cell surface receptor. Proc. Natl. Acad. Sci. USA. 82:1494-1498.

14. Slomiany, A., E. Zdebska, and B. L. Slomiany. 1984. Structures of the neutral oligosaccharides isolated from active human gastric mucin. J. Biol. Chem. 259:14743-14749.

15. Hoskins, L. C., M. Agustines, W. B. McKee, E. T. Boulding, M. Kriaris, and G. Niedermeyer. 1985. Mucin degradation in human colon ecosystems. Isolation and properties of fecal strains that degrade $\mathrm{ABO}$ blood group antigens and oligosaccharides from mucin glycoproteins. $J$. Clin. Invest. 75:944-953.

16. Stanley, R. A., S. P. Lee, and A. M. Roberton. 1983. Heterogeneity in gastrointestinal mucins. Biochim. Biophys. Acta. 760:262-269.

17. Norin, K. E., B. E. Gustafsson, B. S. Lindblad, and T. Midtvedt. 1985. The establishment of some microflora associated biochemical characteristics in feces from children during the first years of life. Acta Paediatr. Scand. 74:207-212.

18. Hoshino, Y., R. G. Wyatt, H. B. Greenberg, A. R. Kalica, J. Flores, and A. Z. Kapikian. 1983. Serological comparison of canine rotavirus with various simian and human rotaviruses by plaque reduction neutralization and hemagglutination tests. Infect. Immun. 41:169-173.

19. Wyatt, R. G., and W. D. James. 1982. Methods of gastroenteritis virus culture in vivo and in vitro. In Virus Infections of the Gastrointestinal Tract. D. A. J. Tyrrell and A. Z. Kapikian, editors. Marcel Dekker, Inc., New York. 13-32.

20. Krah, D. L., and R. L. Crowell. 1982. A solid phase assay of solubilized HeLa cell membrane receptors for binding group B coxsackieviruses and polioviruses. Virology. 118:148-156.
21. Vonderfecht, S. L., A. C. Huber, J. Eiden, L. C. Mader, and R. H. Yolken. 1984. Infectious diarrhea of infant rats produced by a rotavirus-like agent. J. Virol. 52:94-98.

22. Yolken, R. H., R. Viscidi, F. Leister, C. Harris, and S. B. Wee. 1986. Enzyme immunoassay for the detection of rotavirus antigen and antibody. In Manual of Clinical Laboratory Immunology. N. R. Rose, H. Friedman and J. L. Fahey, editors. American Society for Microbiology, Washington, D.C. 573-581.

23. Tidwell, R. R., J. D. Geratz, and E. J. Dubovi. 1983. Aromatic amidines: comparison of their ability to block respiratory syncytial virus induced cell fusion and to inhibit plasmin, urokinase, thrombin, and trypsin. J. Med. Chem. 26:294-298.

24. Greenberg, H., V. McAuliffe, J. Valdesuso, R. Wyatt, J. Flores, A. Kalica, Y. Hosino, and N. Singh. 1983. Serological analysis of the subgroup protein of rotavirus using monoclonal antibodies. Infect. Immun. 39:91-99.

25. Kalica, A. R., J. Flores, and H. Greenberg. 1983. Identification of the rotaviral gene that codes for haemagglutination and protease-enhanced plaque formation. Virology. 125:194-205.

26. Markwell, M. A. K. 1982. A new solid-state reagent to iodinate proteins. I. Conditions for the efficient labeling of antiserum. Anal. Biochem. 125:427-432.

27. Laemmli, U. K. 1970. Cleavage of structural proteins during assembly of the head of bacteriophage T4. Nature (Lond.). 227:680-685.

28. Rostam-Abadi, H., and T. G. Pistole. 1982. Lipopolysaccharidebinding lection from the horseshoe crab, Limulus polyphemus, with specificity for 2-keto-3-deoxyoctonate (KDO). Dev. Comp. Immunol. 6: 299-318.

29. Muresan, V., V. Iwanij, A. D. J. Smith, and J. D. Jamieson. 1982. Purification and use of limulin: a sialic acid-specific lectin. J. Histochem. Cytochem. 30:938-946.

30. Greenberg, H. B., J. Valdesuso, K. vanWyke, M. Midthun, M. Walsh, V. McAuliffe, R. C. Wyatt, A. R. Kalica, J. Flores, and Y. Hoshino. 1983. Production and preliminary characterization of monoclonal antibodies directed at two surface proteins of rhesus rotavirus. J. Virol. 47: 267-275.

31. Hoshino, Y., M. M. Sereno, K. Midthun, J. Flores, A. Z. Kapikian, and R. M. Chanock. 1985. Independent segregation of two antigenic specificities (AP3 and VP7) involved in neutralization of rotavirus infectivity. Proc. Natl. Acad. Sci. USA. 82:8701-8704.

32. Bastardo, J. W., and I. H. Holmes. 1980. Attachment of SA-11 rotavirus to erythrocyte receptors. Infect. Immun. 29:1134-1140.

33. Keljo, D. J., and A. K. Smith. 1986. Unusual properties of rotavirus binding. Pediatr. Res. 20:242a. (Abstr.)

34. Eiden, J., H. M. Lederman, S. Vonderfecht, and R. H. Yolken. 1986. T-cell deficient mice display normal recovery from experimental rotavirus infection. J. Virol. 57:706-708.

35. Carlson, S. E. 1985. N-Acetylneuraminic acid concentrations in human milk oligosaccharides and glycoproteins during lactation. Am. J. Clin. Nutr. 41:720-726.

36. Hauttecoeur, B., S. Sonnino, and R. Ghidoni. 1985. Characterization of two molecular species $\mathrm{G}_{\mathrm{C} 3}$ ganglioside from bovine buttermilk. Biochim. Biophys. Acta. 833:303-307.

37. Yolken, R. H., C. A. Bishop, T. R. Townsend, E. A. Bolyard, J. G. Bartlett, G. W. Santos, and R. Saral. 1982. Infectious gastroenteritis in bone-marrow transplant recipients. N. Engl. J. Med. 306:1009-1012.

38. Losonsky, G., J. Johnson, J. A. Winkelstein, and R. H. Yolken. 1986. The oral administration of human serum immunoglobulin in immunodeficient patients with viral gastroenteritis: a pharmacokinetic and functional analysis. J. Clin. Invest. 76:2362-2367.

39. Rotbart, H. A., R. H. Yolken, W. L. Nelson, D. David, M. H. Roe, and M. J. Levin. 1985. Confirmatory testing of rotazyme results in neonates. J. Pediatr. 107:289-292.

40. Snyder, J. D., D. K. Podolsky, and W. A. Walker. 1986. The role of mucus in intestinal host defense: development differences in composition and binding to cholera toxin. Pediatr. Res. 20:249a. (Abstr.) 